International Journal of Medical Anesthesiology 2020; 3(1): 99-101

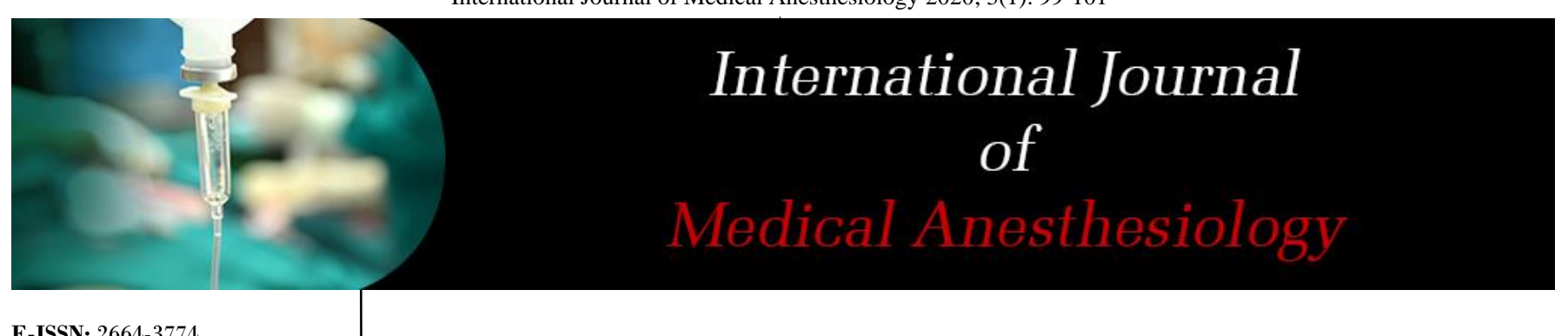

E-ISSN: 2664-3774

P-ISSN: 2664-3766

www.anesthesiologypaper.com

IJMA 2020; 3(1): 99-101

Received: 16-11-2019

Accepted: 19-12-2019

Dr. Jitesh Marian Rasquinha Associate Professor,

Department of Anesthesiology,

Kanachur Institute of medical

Sciences, Deralakatte,

Mangalore, Karnataka, India
Corresponding Author: Dr. Jitesh Marian Rasquinha Associate Professor, Department of Anesthesiology, Kanachur Institute of medical Sciences, Deralakatte,

Mangalore, Karnataka, India

\section{A study of complications: A comparative pain score evaluation of lumbar epidural block using $0.5 \%$ bupivacaine and $0.5 \%$ bupivacaine with ketamine}

\author{
Dr. Jitesh Marian Rasquinha
}

DOI: https://doi.org/10.33545/26643766.2020.v3.i1b.75

\section{Abstract}

Intrathecal and epidural administration of opioids are widely used even now. Opioid administration intrathecally or epidurally causes dependable method of pain relief without affecting motor functions or other sensory modalities such as touch sensation. This study is an effort to find the complications of lumbar epidural block using $0.5 \%$ bupivacaine vs $0.5 \%$ bupivacaine with ketamine.

Keywords: Epidural, bupivacaine, ketamine, complications

\section{Introduction}

Intrathecal and epidural administration of opioids are widely used even now. Opioid administration intrathecally or epidurally causes dependable method of pain relief without affecting motor functions or other sensory modalities such as touch sensation ${ }^{[1-3]}$. But this method of pain relief still has some drawbacks, the most serious of which appears to be delayed respiratory depression especially with hydrophilic drug like morphine. Other adverse effects commonly seen are urinary retension, pruritus, Development of tolerance, somnolence and inefficiency against certain types of pain. In higher doses intraspinal opioids can cause hyperesthesia ${ }^{[4,5]}$.

Life threatening complication of intra spinal morphine in the form of delayed respiratory depression limit it's usage in the present era of day care surgery and anaesthesia ${ }^{[6,7]}$.

This study is an effort to find the complications of lumbar epidural block using $0.5 \%$ bupivacaine vs $0.5 \%$ bupivacaine with ketamine.

\section{Aims and Objectives}

This study is an effort to find the efficacy of lumbar epidural block using $0.5 \%$ bupivacaine vs $0.5 \%$ bupivacaine with ketamine.

\section{Materials and Methods}

A prospective randomized double-blind study was conducted in 60 patients admitted at for various elective surgical procedures during the period 2018 -2009. Surgical procedures which required blockade below T6 dermatome was only selected.

\section{Inclusion criteria}

- ASA physical status - I- patients

- Both male and female

- 20 -40 years age groups

- Weight $40-90 \mathrm{kgs}$

\section{Exclusion Criteria}

- Difficult airway

- Previous history of anaesthetic complications

- History of local anaesthetic allergy

- Spinal deformities

- Preexisting neurological deficits

- Cases with contra indication to regional anaesthesia 
Total sample sizes of 60 patients were randomly allocated into two groups. Control groups-Group-I-received $0.5 \%$ bupivacaine, $1.5 \mathrm{ml}$. spinal segment to be blocked $(\mathrm{n}=30)$ : (Not exceeding $2 \mathrm{mg} / \mathrm{kg}$ body weight) and Group-II(n=30) received bupivacaine $0.5 \% \quad 1.5 \mathrm{ml}$.spinal segment to be blocked plus preservative free $1 \%$ ketamine in a dose of 0.5mg.kg body weight.

On the previous day of surgery, a detailed pre anaesthetic evaluation were done in all cases. Procedure was explained and written informed consent were obtained from the patients and relatives. All patients were kept nil per oral from 10.00 P.M on the previous day of surgery and premedicated with tablet. Diazepam $0.2 \mathrm{mg} . \mathrm{kg}$ body weight.

\section{Procedure}

On the day of surgery, in the operating room 18-gauge intravenous cannula was placed in a peripheral vein in the non-dominant upper limb and patients were connected to monitors. Non-invasive blood pressure (NIBP). Pulse oximetry and continuous ECG were recorded on Philips monitor (Agilent 1204 A model). All patients received intravenous premeditation with Injection diazepam $0.2 \mathrm{mg} . \mathrm{kg}$ body weight mixed with $21.3 \mathrm{mg}$ of lignocaine $2 \%$ over 5 minutes. Base line blood pressure and heart rate were recorded. All parents were preloaded with intravenous fluidringer lactate $10 \mathrm{ml} . \mathrm{kg}$ body weight before performing epidural block.
All patients were put is left lateral position and under all aseptic precautions lumbar L3-L4 interspace was identified and infiltrated with $1 \mathrm{ml}$ of $2 \%$ Lignocaine. Epidural space were identified by introducing a 18 gauge Tuohy needle using loss of resistance technique. Group-I-patients $(n=30)$ received bupivacaine $0.5 \% 1.5 \mathrm{ml}$. spinal segment to be blocked and Group-II-Patients $(n=30)$ received bupivacaine $0.5 \% 1.5 \mathrm{ml}$. spinal segment to be blocked plus preservative free ketamine $1 \%, 0.5 \mathrm{mg} . \mathrm{kg}$ body weight as single shot epidurals. Patients were made to lie down supine and an independent fellow resident recorded the following study parameters. The intra and post-operative complications were noted and reported.

\section{Results}

Table 1: Distribution of patients according to complications

\begin{tabular}{|c|c|c|c|c|c|}
\hline Hypotension & 2 & 6.7 & 0 & 0.0 & $\#$ \\
\hline Bradycardia & 3 & 10.0 & 0 & 0.0 & $\#$ \\
\hline Shivering & 4 & 13.3 & 2 & 6.7 & 0.43 \\
\hline Shivering \& Urinary retention & 3 & 10.0 & 2 & 6.7 & 0.99 \\
\hline Urinary retention & 3 & 10.0 & 1 & 3.3 & 0.52 \\
\hline Hallucinations & 0 & 0.0 & 1 & 3.3 & $\#$ \\
\hline Total & 15 & 50.0 & 6 & 20.0 & $2.17 *$ \\
\hline
\end{tabular}

* Significant at $P<0.05$

\# Statistical comparison not possible

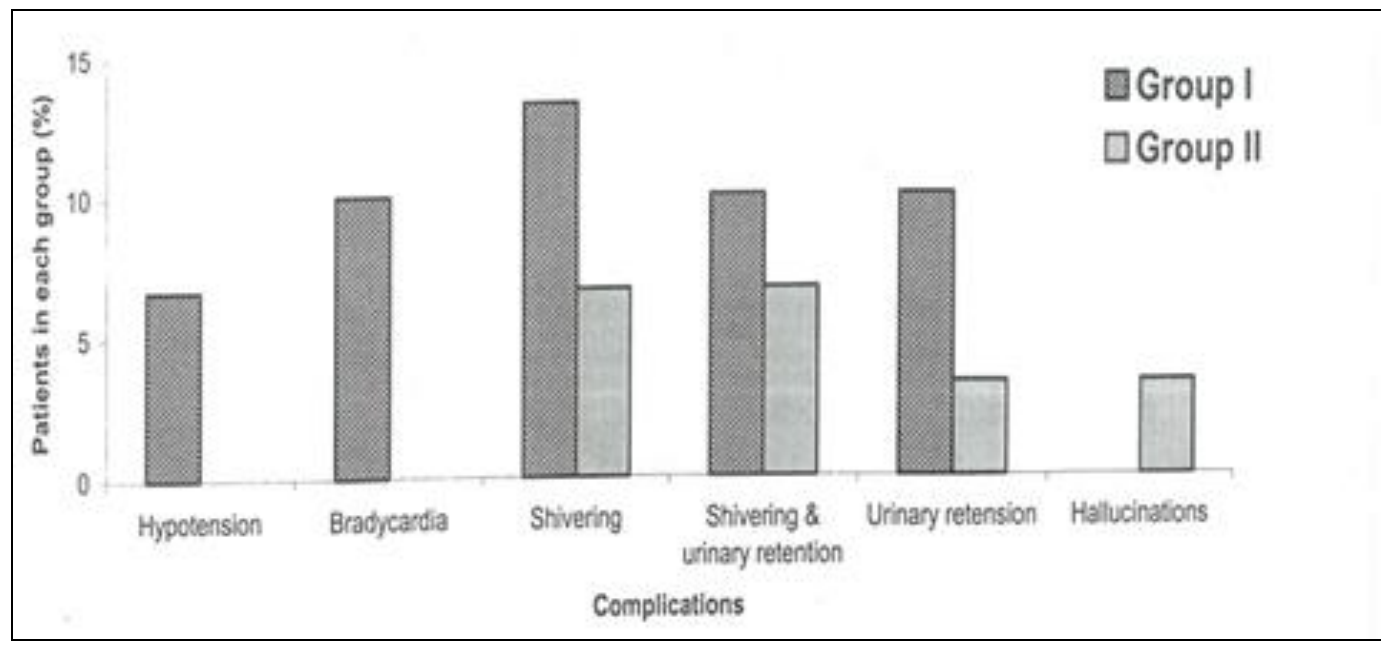

Fig 1: Distribution of patients according to complications, $n=30$ in each of Group I and Group II

\section{Discussion}

Table 1 and figure 1 shows distribute of patients according to complications. It was observed that the percentage of patients with shivering, Shivering and urinary retention, and urinary retention were not significantly different between the two groups. However, the overall percentage of patients with post-operative complications were significantly lower in Group II (20.0\%) than that in Group I (50\%) (Table 11; $P<0.05$, based on normal distribution $\mathrm{Z}$-test).

In our study we found that Intra and postoperative complications were comparable between bupivacaine plus ketamine group and bupivacaine group. However, over all complications were more in bupivacaine group (Statistically significant $p<0.05)$. Clinically hypotension requiring vasopressor therapy were seen in 2 patients and bradycardia requiring treatment with injection atropine were seen in 3 patients. This side effects were not observed in bupivacaine plus ketamine group probably because of the sympathetic stimulation caused by ketamine. This observation correlates with the study of Jankovic Z et al. (1999) ${ }^{[3]}$. They did a randomized double-blind study to know the effects of intra operative epidural administration of ketamine added to bupivacaine compared with fentanyl added to bupivacaine. One group received $20 \mathrm{~m} 1$ of $0.125 \%$ bupivacaine plus 50 mcg of fentanyl and other group received $20 \mathrm{ml}$ of $0.125 \%$ bupivacaine plus $50 \mathrm{mg}$ ketamine. They observed higher systolic blood pressure in ketamaine bupivacaine group. No statistically significant difference between groups in heart rate during operation. They also observed that fentanyl added to bupivacaine caused higher incidence of hypotension than ketamine added to bupivacaine.

In our study shivering was also less in bupivacaineketamine group (67\%) when compared to plain bupivacaine group $(13.3 \%)$. This result can also be attributed to the sympathetic stimulation caused by ketamine. 
One patient in bupivacaine plus ketamine group had hallucinations. In our study we found that ketamine in adose of $0.5 \mathrm{mg} . \mathrm{kg}$ body weight combined with $0.5 \%$ bupivacaine in lumbar epidural block provided good postoperative analgesia and low mean pain score (modified visual analogue scale). But this result does not correlated with the study of Weir PS et al. (1998) [2] who concluded that addition of ketamine even at a dose of $0.67 \mathrm{mg} . \mathrm{kg}$ along with $0.5 \%$ bupivacaine did not improve extra dual block in adult patients undergoing total knee replacement: In our study majority of the patients in both groups were operated for inguinal herniorraphy. Pain produced by a total knee replacement may be much more severe than an Inguinal herniorraphy pain. This may explain the inefficiency of epidural ketamine to relieve postoperative pain in Weir PS et al. study, since the intensity of pain can vary with different surgical procedures.

In our study we found that Intra and postoperative complications were comparable between bupivacaine plus ketamine group and bupivacaine group. However, over all complications were more in bupivacaine group (Statistically significant $p<0.05)$. Clinically hypotension requiring vasopressor therapy were seen in 2 patients and bradycardia requiring treatment with injection atropine were seen in 3 patients. This side effects were not observed in bupivacaine plus ketamine group probably because of the sympathetic stimulation caused by ketamine. This observation correlates with the study of Jankovic Z et al. (1999) ${ }^{[3]}$. They did a randomized double-blind study to know the effects of intra operative epidural administration of ketamine added to bupivacaine compared with fentanyl added to bupivacaine. One group received $20 \mathrm{~m} 1$ of $0.125 \%$ bupivacaine plus 50 mcg of fentanyl and other group received $20 \mathrm{ml}$ of $0.125 \%$ bupivacaine plus $50 \mathrm{mg}$ ketamine. They observed higher systolic blood pressure in ketamaine bupivacaine group. No statistically significant difference between groups in heart rate during operation. They also observed that fentanyl added to bupivacaine caused higher incidence of hypotension than ketamine added to bupivacaine.

In our study shivering was also less in bupivacaineketamine group (67\%) when compared to plain bupivacaine group $(13.3 \%)$. This result can also be attributed to the sympathetic stimulation caused by ketamine.

One patient in bupivacaine plus ketamine group had hallucinations. In our study we found that ketamine in adose of $0.5 \mathrm{mg} . \mathrm{kg}$ body weight combined with $0.5 \%$ bupivacaine in lumbar epidural block provided good postoperative analgesia and low mean pain score (modified visual analogue scale). But this result does not correlated with the study of Weir PS et al. (1998) [2] who concluded that addition of ketamine even at a dose of $0.67 \mathrm{mg} . \mathrm{kg}$ along with $0.5 \%$ bupivacaine did not improve extra dual block in adult patients undergoing total knee replacement: In our study majority of the patients in both groups were operated for inguinal herniorraphy. Pain produced by a total knee replacement may be much more severe than an Inguinal herniorraphy pain. This may explain the inefficiency of epidural ketamine to relieve postoperative pain in Weir PS et al. study, since the intensity of pain can vary with different surgical procedures.

In our study we used preservative free $1 \%$ ketamine $0.5 \mathrm{mg} . \mathrm{kg}$ body weight epidurally with $0.5 \%$ bupivacaine in the study group. Lowest and highest dose of ketamine used in the present study were $23.5 \mathrm{mg}$ and $37.5 \mathrm{mg}$ respectively.
Out of 30 patients $50 \%$ patients received ketamine in a dose less than $30 \mathrm{mg}$ and $50 \%$ of patients received ketamine in a dose of $30 \mathrm{mg}$ or more. Clinically there was no difference with in this groups regarding postoperative analgesia. Patient who received $26.5 \mathrm{mg}$ epidural ketamine had postoperative analgesia for 620 minutes whereas patient who received $37.5 \mathrm{mg}$ of epidural ketamine had 495 minutes of postoperative analgesia. Our study did not correlated with the study of Gebhardt B (1994) [3] who after controlled study concluded that the minimum dose of epidural ketamine for post-operative analgesia is $30 \mathrm{mg}$ and less than $30 \mathrm{mg}$ is ineffective in controlling postoperative pain.

\section{Conclusion}

In our study we found that Intra and postoperative complications were comparable between bupivacaine plus ketamine group and bupivacaine group. However, over all complications were more in bupivacaine group.

\section{References}

1. Yang CY, wong CS, Chang JY, Ho ST. Intrathecal ketamine reduces morphine requirements in patients with cancer pain. Can. J. Anaesth. 1996; 43(4):379-383.

2. Weir PS, Fee JP. Double blind comparison of extradural block with three bupivacaine-ketamine mixtures in knee arthroplasty Br. J. Anaesth. 1998; 80(3):299-301.

3. Jankovic Z, Stamenkovic D, Milosavljevic S, Pescko P. Epidural analgesia in total gastrectomy-combination of bupivacaine with ketamine or fentanyl. Acta Chir Iugos 1. 1999; 46(1-2):47-52.

4. Mankowitz E, Brock Utne JG, Consnett JE, GreenThompson R. Epidural ketamine a preliminary report. S. Afr. Med J. 1982; 61(12):441-2

5. Naguib M, Adu-Gyamfi Y, Absood GH, Farag H, Gyasi HK. Epidural ketamine for post-operative analgesia. Can Anaesth Soc J. 1986; 33(1):16-21.

6. Kawana Y, Sato H, Shimada H, Fujita N, Veda Y, Hayashi A et al. Epidural ketamine for postoperative pain relief after gynaecologic operations: a double-blind study and comparisons with epidural morphine: Anesth Analg 1987; 66(8):735-738.

7. Peat SJ, Bras P, Hanna MH. A double-blind comparison of epidural ketamine and diamorphine for postoperative analgesia: Anaesthesia. 1989; 44(7):555558. 